LA $-10242-$ MS

DE85 005331

\title{
Water and Contaminant Movement: Migration Barriers
}

\author{
Leonard J. Lane \\ John W. Nyhan
}

\begin{abstract}
DISCLAIMER
This report was prepared as an account of work sponsored by an agency of the United States Government. Neither the United States Government nor any agency thereof, nor any of their employees, makes any warranty, express or implied, or assumes any legal liability or responsibility for the accuracy, completeness, or usefulness of any information, apparatus, product, or process disclosed, or represents that its use would not infringe privately owned rights. Reference herein to any specific commercial product, process, or service by trade name, trademark, manufacturer, or otherwise does not necessarily constitute or imply its endorsement, recommendation, or favoring by the United States Government or any agency thereof. The views and opinions of authors expressed herein do not necessarily state or reflect those of the United States Government or any agency thereof.
\end{abstract}

\section{MASTER}




\title{
WATER AND CONTAMINANT MOVEMENT: MIGRATION BARRIERS
}

\author{
by
}

\author{
Leenard J. Lane and John W. Nyhan
}

\begin{abstract}
Migration barriers are used in shallow land burial facilities to slow or stop the movement of water and contaminants and are discussed here as a single component embedded in a complex environmental system. Analytical solutions to solute transport equations are used to approximate the behavior of migration barriers and to derive design criteria for control of subsurface water and contaminant migration. Various types of migration barriers are compared and design recommendations are made for shallow land burial trench caps and liners. Needed improvements and suggested field experiments for future designs of migration barriers are then discussed relative to the management of low-level radioactive wastes.
\end{abstract}

\section{INTRODUCTION}

Currently, solid, low-level radioactive wastes are often buried in shallow, unlined pits, which are capped with a few feet of soil. Depending on the nature of the waste and the operational procedures at the disposal site, the waste may be dumped or placed, in an orderly fashion, in the trench. Soil backfill is then compacted to some extent and the surface is usually mounded to minimize ponding of precipitation.

The following events illustrate typical performance that might occur at an existing disposal installation (Meyer 1976):

1. The trench is excavated from soils that have relatively low permeability.

2. Porous, cornpressible wastes containing organics and a wide range of chemical forms are then placed in the trench. Filled trenches may have as much as $30 \%$ void space (Papadopoulos and Winograd 1974).

3. The wastes are covered with an earthen cap, which is often more permeable than the original in situ soil and rock. This usually creates an infiltration gallery.
4. Some of the precipitation that falls on the cap infiltrates into the trench and soaks the wastes.

5. Leaching of the wastes begins, aided by the presence of organic matter, bacterial action, and chelating agents (Duguid 1975).

6. Trench leachate begins to (a) migrate downward and laterally because of the hydraulic head imposed by the leachate in the trench and/or to (b) overflow at the surface in springs and in seeps at some low point between the cap and the undisturbed soil.

7. As the wastes are soaked and leached, they compact, undermining the cap. Surface cracking results so that infiltration into the trench is increased and more leachate is generated.

The Department of Energy, through the National Low-Level Waste Management Program, is supporting research to develop subsurface water management technology to understand and control water and radionuclide migration. Migration barriers are often offered as a simplified solution to a suite of complex, interdependent problems in subsurface water management. However, shallow land burial 
(SLB) systems are complex systems with interactive surface, near-surface, and subsurface processes, which control the rates and routes of water and contaminant movement.

Therefore, migration barriers, which are defined as natural or artificial materials (used in caps, liners, or other layers in the SLB trench) designed to slow or stop the movement of water and contaminants, are but a single component embedded within a complex system. Subsequen: discussion will focus on soil and material properties, solute properties, and geometric properties affecting water and contaminant movement. However, this does not mean that we do not recognize or fail to emphasize the interactive nature of SLB systems as described by Hakonson et al. (1982a). Moreover, specific technologies are available to compute a water balance in the surface and near-surface areas (Knisel 1980. Nyhan and Lane 1982. Lane 1984, Lane and Stone 1983). When the surface water balance is computed, it can be used to specify the upper boundary conditions for subsurface water transport calculations. Once the water movement data are calculated and if the chemical source terms can be specified, then solute transport equations can be applied to compute contaminant movement (see Polzer and Lane 1984 for experimental designs to determine leaching rate mechanisms and thus source terms for subsequent transport calculations).

There is a need for evaluation of migration barriers, but that evaluation must be in the context of a component evaluation analysis as part of a complex and interactive SLB systems analysis. These analyses are being reported elsewhere and Integrated Systems Tests are under way at Los Alamos.

We use analytic solutions to the solute transport equations (under unsaturated flow conditions relevant to pending and future modeling requirements involving 10 CFR 61 and DOE order 5820.2) to approximate the behavior of migration barricrs. These solutions are then used to derive design criteria (i.c., barrier thickness as a function of pore water velocity and pore water velocity as a function of material characteristics of the barriers) for control of subsurface water and contaminant migration.

\section{A. Background}

The Los Alamos National Laboratory developed the Experimental Engineered Test Facility (see DePoorter and Hakonson 1982 and DcPoorter et al. 1982 for a description of the facilities and early experimental designs) as a resource to aid in determining migration potential for water and contaminants at arid and semiarid SLB facilities. A com2 prehensive description of results as of FY 1983 was recently prepared by Hakonson et al. (1983). This report contained a number of reprints attached as numbered appendixes or numbered references as appendixes.

The hydraulic properties of crushed tuff (a sandy silt textural analog) were described (Abeele and DePoorter 1983), as well as the results of a tracer study that was used to derive estimates for dispersion coefficients and retardance factors (Lane 1983) and preliminary documentation of an advanced flow and transport model for subsurface flow (Travis 1984).

The references cited above provide a comprehensive source of background information on the Experimental Engineered Test Facility and a summary of results froin related research projects as of October 1983. These documents aiso provide the necessary background information for the migration barrier results reported here.

\section{B. Water Management}

Movement of water in the liquid phase in soil can be described by combining Darcy's equation and the continuity equation to produce Richard's equation (see Hillel 1971 or Skaggs and Khaleel 1982 for derivations). Vertical (one-dimensional) and unsaturated flow, q. can be written using Darey's Law as

$q=-k \partial h / d z$

where $q$ is the water flow per unit area $(\mathrm{m} / \mathrm{sec}$ or $\mathrm{cm} / \mathrm{yr})$ and $\mathrm{k}$ is the hydraulic conductivity $(\mathrm{m} / \mathrm{sec}$ or $\mathrm{cm} / \mathrm{yr}$ ). The hydraulic conductivity is a function of the volumetric water content (often normalized to relative saturation by dividing the water content at saturation), $h$ is $\psi-z=$ total soil water potential (m or $\mathrm{cm}), \mathrm{z}$ is the distance below the soil surface $(\mathrm{nl}$ or $\mathrm{cm})$, and $\psi$ is the matric potential of the soil ( $\mathrm{m}$ or $\mathrm{cm}$ ).

The important concept illustrated by $\mathrm{Eq}(1)$ is that the flow rate, $q$, is a function of the hydraulic gradient, $\partial \mathrm{h} / \partial \mathrm{z}$, and the hydraulic conductivity. Moreover [not illustrated by Eq (1)], it is significant that the hydraulic conductivity, $k(\theta)$, is a very strong function of water content in the soil. Variations in $\theta$ on the order of 2 can cause variations in $k(\theta)$ over orders of magnitude. For example, the crushed tuff referred to earlier has a $k-\theta$ relationship (Abeele and DePoorter 1983) with hydraulic conductivities varying over a range of from about $10^{-9} \mathrm{~m} / \mathrm{sec}$ for $\theta$ at about $15 \%$ to more than $10^{-6} \mathrm{~m} / \mathrm{sec}$ for $\theta$ at about $30 \%$. Therefore, a twofold change in volumetric water content resuited in about a 1000-fold change in hydraulic conductivity. 
The significance of this highly nonlinear relationship is obvious. Surface and subsurface water management technologies that have a strong influence on soil water content also have a very strong influence on water and contaminant migration potential. We will elaborate on this aspect of contaminant migration control in a later section of this report.

\section{Solute Transport}

Simplified modeis for solute transport in the unsaturated zone lump the effects of several processes. These processes relate solute concentration to concentration in the solid phase in a distribution coefficient, $K_{d}$. This can best be illustrated in the form of a retardation factor in the one-dimensional convective-dispersive solute transport cquation written as

$\mathbf{R} \frac{\partial \mathrm{c}}{\partial \mathrm{t}}=\mathrm{D} \frac{\partial^{2} \mathrm{c}}{\partial \mathrm{x}^{2}}-\mathrm{v} \frac{\partial \mathrm{c}}{\partial \mathrm{x}}-\mu \mathrm{c}+\gamma$,

where $\mathbf{R}$ is a retardation factor, $\mathrm{c}$ is the solute concentration in $\mathrm{mg} / \mathrm{R}, \mathrm{t}$ is time in days, $\mathrm{D}$ is an apparent dispersion coefficient in $\mathrm{cm}^{2} / \mathrm{d}, \mathrm{x}$ is distance in $\mathrm{cm}, \mathrm{v}$ is the pore water velocity [computed as q from Eq (1) divided by $\theta$ )] in $\mathrm{cm} / \mathrm{d}, \mu$ is a first-order decay constant in $1 / \mathrm{d}$, and $\gamma$ is a zero-order production constant in $\mathrm{mg} / \mathrm{l} / \mathrm{d}$.

The retardation factor, $R$, can be written as

$R=1+\rho K_{d} / \theta$,

where $\rho$ is the bulk density in $\mathrm{g} / \mathrm{cm}^{3}, K_{\mathrm{d}}$ is the distribution coefficient in $\mathrm{m} / \mathrm{g}$. and $\theta$ is the volumetric water content. The distribution coefficient. $K_{d}$ can, in turn, be written as

$K_{d}=s / c$,

where $s$ is the concentration in the solid phase in parts per million or $\mu \mathrm{g} / \mathrm{g}$ and $\mathrm{c}$ is the solute concentration in $\mathrm{mg} / \mathrm{l}$. A significant assumption in Eq. (4) is that the solid and solute concentrations are at equilibrium, which means that flow velocities are low enough that equilibrium does occur.

Physical processes, such as the relative amount of mobile and immobile water involved in unsaturated flow, fracture flow, nonhomogeneous conductivities, etc., can affect solute transport (Amoozegar-Fard et al. 1982 and Wierenga 1977). The dispersion coefficient, $D$, can be related to micro- and macroprocesses through the effective dispersion coefficient as

$\mathrm{D}=\mathrm{D}_{\mathrm{o}} \tau+\lambda v$

where $D$ is the effective dispersion coefficient in $\mathrm{cm}^{2} / \mathrm{d}, D_{\mathrm{o}}$ is the diffusion coefficient in $\mathrm{cm}^{2} / \mathrm{d}, \tau$ is a tortuosity factor, $\lambda$ is the dispersivity in centimeters, and $\mathrm{v}$ is the pore velocity in $\mathrm{cm} / \mathrm{d}$. The dispersivity, $\lambda$, is usually assumed to be a constant but may vary with travel time and travel distance. Hence, there is a question of scale factors. The alue of $v$ in $\mathrm{Eq}(5)$ is taken as the mean pore water velocity, but it actually has a distribution about the mean value, and dispersivity (and other parameters) can differ for the longitudinal and lateral directions (Simmons 1982). Under these conditions, the one-dimensional equations need to be extended to two or three dimensions. Finally, methods are needed that accurately reflect layered soil systems.

In spite of the above qualifications or cautionary remarks about the underlying assumptions in Eqs (1-5), the equations can be useful in applying analytic solutions to the problem of migration barriers.

\section{Analytic Solutions}

If we assume that the flux, $q$, and thus the pore water velocity, $\mathrm{v}$, in $\mathrm{Eq}(2)$ is constant (steady-state flow assumption), the analytic solutions to $E q(2)$ arc readily obtainable (see van Genuchien and Alves 1982 for an extensive list of analytic solutions). The benefit of an analytic solution is that one can directly solve. and thus more easily manipulate, the equations to examine the influence of parameters in the model. This is not to say one cannot perform similar calculations using numerical solutions to more complex formulations of the governing equations, but, for the purposes here, analytic solutions appear to be more useful.

In an analysis of solutions to Eq (2), Apps ct al. (1982) showed that under most conditions the constant concentration boundary condition resulted in more conservative (thicker migration barriers) estimates than did the constant flux boundary condition. Therefore, we use the analytic solution to the constant concentration boundary condition as described by

$c(0, t)=\left\{\begin{array}{lc}c_{o} & 0 \leq t \leq t_{o} \\ 0 & t>t_{o}\end{array}\right.$. 
where $c_{o}$ is the constant concentration present at the "upper" boundary of the migration barrier. Three special cases of Eq (6) are of interest. First, in the limit as $t_{0}$ approaches zero, then Eq (6) describes an impulsive input and the solution to Eq (2) subject to Eq (6) is called the impulse response. Details of this particular analytic solution are given by $\mathrm{Yu}$ et al. (1984). The second case is when $t_{0}$ and $c_{o}$ are finite. This is called the pulse input, with the solution of Eq (2) subject to a pulse input termed the pulse response. The final case is when $c_{o}$ is finite but $t_{0}$ approaches infinity. Under these conditions, $c(x, t)$ approaches $c(x)$ as the steady-state response or steady-state solution (see van Genuchten and Alves 1982 for solutions to the pulse input, particularly p. 60).

The impulse response is an input-time-independent measure of the system's response. It can be used as an approximation of how a very short pulse of highly concentrated contaminant might move through a migration barrier. The pulse response can be used to see how a "square wave" input pattern is dispersed as it moves through the migration barricr. Finally, the infinite $t_{n}$ or steady-state solution can be used to determine how long it might take before steady state is reached and, from this, how long it takes the concentration at the end of a migration barrier (output) to become equal to the concentration at the "upstream boundary" or source (input).

\section{E. Scope and Limitations}

This report. as described above, uses analytic solutions to Eqs (1-6) to approximate the behavior of migration barriers, defined as natural or artificial materials (liners, layers, structures) designed to slow or stop the movement or migration of water and contaminants from SLB systems. Because of the strong surface-subsurface interactions described above, a report describing migration barriers and their behavior cannot be a "stand alone" document. Nature. and SLB systems as a subset of nature, is not simple enough that migration barriers can be considered independently of other components affecting water and contaminant dynamics. Therefore, this report is limited to migration barriers and is dependent on the reference material reported by Hakonson et al. (1982a and 1983) and Lane (1984).

Many of the field data used as a data base for the modeling approximations of migration barrier behavior were collected during FY 1982 and
1983. Detailed and improved experiments are under way in FY 1984. A previous report deals, in detail, with artificial or manmade materials for barriers (Pertusa 1980), but this report primarily deals with natural materials such as soils and clays.

\section{SOII. AND MATERIAL PROPERTIES AF- FECTING MIGRATION}

In this section, properties of soils and clays (note there are clay soils and mineral clays) are described and related to their potential for development of migration barriers. Hydraulic conductivity of soils by texture class, as described below, is based on information published by Rawls et al. (1982). Hydraulic properties of soils (based on 1300 soils in 32 states) were summarized in texture triangle plots, information published by Lane and Stone (1983) summarizing soil properties by textural class [based on Rawls et al. (1982) data], and information published in an additional report (Lane 1984).

\section{A. Saturated Hydraulic Conductivity of Soils by Textural Class}

Table I lists 12 soils by textural class and indicates representative values of percentages of sand. silt, and clay and rough estimates of the associated saturated hydraulic conductivity. Notice that the values of hydraulic conductivity in Table I range from a low of $440 \mathrm{~cm} / \mathrm{yr}$ to a high of $380000 \mathrm{~cm} / \mathrm{yr}$. or a ratio of $380000 / 440=864$. Thus, there is nearly a 1000-fold range in saturated hydraulic conductivity across the 12 soil textural classes shown in Table $\mathrm{I}$.

\section{B. Saturated Hydraulic Conductivity of Uncom- pacted and Compacted Clays and Tuff}

Table II lists estimates of saturated hydraulic conductivity for uncompacted and compacted clays and tuff. Notice that the process of compaction produces a reduction in saturated hydraulic conductivity on the order of a factor of 10 . Also notice that. except for the crushed tuff, most values in Table II are 1 to 3 or more orders of magnitude less than the values for soils shown in Table I. Again. Table I describes soils and Table II emphasizes clays rather than soils in a textural context. 


\section{TABLE I}

\section{APPROXIMATE COMPOSITION (SAND, SILT, AND CLAY) OF 12 SOIL TEXTURAL CLASSES AND THEIR ASSOCIATED SATURATED HYDRAULIC CONDUCTIVITIES}

\begin{tabular}{|c|c|c|c|c|}
\hline \multirow{2}{*}{$\begin{array}{c}\text { Soil Texture } \\
\text { Class }\end{array}$} & \multicolumn{3}{|c|}{$\begin{array}{l}\text { Representative } \\
\text { Composition } \\
\text { as Percent } \\
\text { by Weight" }\end{array}$} & \multirow{2}{*}{$\begin{array}{l}\text { Approximate Central Range } \\
\text { for the Representative } \\
\text { Saturated Hydraulic } \\
\text { Conductivity (cm/yr) }\end{array}$} \\
\hline & Clay & Silt & $\overline{\text { Sand }}$ & \\
\hline Sand & 3 & 7 & 90 & $1.0 \times 10^{5}-3.8 \times 10^{5}$ \\
\hline Loamy Sand & 5 & 15 & 80 & $3.1 \times 10^{4}-1.0 \times 10^{5}$ \\
\hline Sandy Loam & 10 & 20 & 70 & $1.5 \times 10^{4}-3.1 \times 10^{4}$ \\
\hline Loam & 20 & 40 & 40 & $8.0 \times 10^{3}-1.5 \times 10^{4}$ \\
\hline Silty Loam & 15 & 65 & 20 & $4.0 \times 10^{3}-8.0 \times 10^{3}$ \\
\hline Silt & 5 & 87 & 8 & $2.7 \times 10^{3}-5.3 \times 10^{3}$ \\
\hline Sandy Clay Loam & 30 & 10 & 60 & $2.2 \times 10^{3}-4.0 \times 10^{3}$ \\
\hline Clay Loam & 35 & 35 & 30 & $1.6 \times 10^{3}-2.2 \times 10^{3}$ \\
\hline Silty Clay Loam & 35 & 55 & 10 & $1.3 \times 10^{3}-1.8 \times 10^{3}$ \\
\hline Sandy Loam & 45 & 5 & 50 & $8.9 \times 10^{2}-1.3 \times 10^{3}$ \\
\hline Silty Clay & 45 & 50 & 5 & $6.7 \times 10^{2}-1.1 \times 10^{3}$ \\
\hline Clay $^{b}$ & 65 & 20 & 15 & $4.4 \times 10^{2}-8.9 \times 10^{2}$ \\
\hline
\end{tabular}


TABLE II

\section{APPROXIMATE SATURATED HYDRAULIC CONDUCTIVITY OF UNCOMPACTED AND COMPACTED CLAYS \\ [Data selected from information presented by Apps et al. (1982) and Abeele (1984)]}

\section{Material Description}

$\mathrm{Na}$ - montmorillonite

clay, uncompacted

$\mathrm{Na}$ - bentonite clay,

uncompacted

Ca-kaolinite clay,

uncompacted

Unweathered marine

clay, uncompacted

Compacted marine

clay

Kaclinite clay,

compacted at

$50 \mathrm{kPa}$

Crushed Bandelier tuff, uncompacted.

$0 \%$ clay

Crushed Bandelier tuff, compacted at $1000 \mathrm{kPa}, 0 \%$ clay

Crushed Bandelier tuff, uncompacted, $\mathrm{i} 0 \%$ clay $^{\mathrm{b}}$

Crushed Bandelier tuff, compacted at $1000 \mathrm{kPa}, 10 \%$ clay
Approximate Saturated
Hydraulic Conductivity
(cm/yr)

Approximate

Porosity

0.69

0.63

0.65

$0.55-0.64$

63-320

3.2

0.30

$0.063-0.63$

0.58

72

0.52

9500

0.38

410

0.52

0.38

0.38

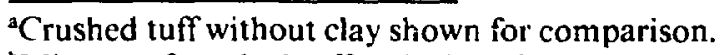

'Mixture of crushed tuff and Wyoming bentonite clay. 


\section{MIGRATION BARRIER CONCEPTS AND CALCULATIONS}

\section{A. Breakthrough Curve Analysis}

The concept of a breakthrough curve (BTC) is illustrated in Fig. I. The curves in Fig. 1 represent the normalized concentration observed at a distance of $100 \mathrm{~cm}$ in a migration barrier, with properties as shown in the figure and subject to an upper boundary condition as $c(0, t)=c_{0}$ for $t \leq t_{0}$ and 0 for $t>t_{0}$. Notice that for very large $t_{0}$, the concentration breaking through the barrier approaches the boundary condition, $c_{0}$, as shown in Fig. 1. The second curve in Fig. $\mathrm{I}$ is for $\mathrm{t}_{0}=50$ years and represents a pulse response or a BTC that never reached steady state. Also notice that for the low $(1 \mathrm{~cm} / \mathrm{yr})$ pore water velocity $(\mathrm{v}=$ $q / \theta)$, the breakthrough takes years.

\section{B. Penetration Time-Barrier Thickness}

Using Fig. 1, we can define a penetration time $t_{p}(\alpha)$ as follows. For a given migration barrier, let $\alpha=$ a fixed $c / c_{o}$ (say $0.10,0.25$, etc.) and let $t_{p}(\alpha)=$ the time until $c / c_{v}=\alpha$ on the BTC. For example, in Fig. 1 , if $\alpha=0.35$, the $t_{p}(0.35)=20 y r$ and if $\alpha=0.80$, then $t_{p}(0.80)=120$ yr. Figure 2 illustrates a plot of penetration times vs migration barrier thickness for a pore water velocity of $v=1.0 \mathrm{~cm} / \mathrm{yr}$ and other material properties of crushed and compacted tuff (see Table II). Table II shows that, at saturation, the pore water velocity $v=q / \theta=410 / 0.38=1079 \mathrm{~cm} / \mathrm{yr}$. F is a value of $\theta=0.11$, the corresponding pore water velocity is $\mathrm{v}=0.1095,0.11=1.0 \mathrm{~cm} / \mathrm{yr}$. Again, this illustrates the importance of moisture content (three orders of magnitude in this example) on unsaturated flow and transport rates.

Although the calculations represented above and in Fig. 2 are for crushed tuff, they are equally valid for other materials if $\mathrm{v}, \mathrm{R}$, and $\mathrm{D}$ are as given and if Eqs (2-5) apply. Figure 3 shows penetration times for $v=$ $100 \mathrm{~cm} / \mathrm{yr}$, which roughly corresponds with $\theta=0.19$ for crushed tuff. Again, notice the significant influence of moisture content, $\theta$.

Penetration times for $\alpha=0.10$, or $10 \%$ of source concentration breaking through the migration barrier vs pore water velocity and barrier thickness, are shown in Fig. 4. For example, with a pore water velocity of $v=10 \mathrm{~cm} / \mathrm{yr}$ and a barrier thickness of $100 \mathrm{~cm}$, we would expect $\mathrm{c} / \mathrm{c}_{\mathrm{o}}=0.10$ at about 3.8 years. If the pore water velocity were $1.0 \mathrm{~cm} / \mathrm{yr}$, the corresponding time would be about $7.4 \mathrm{yr}$ (see the curve labeled $100 \mathrm{~cm}$ in Fig. 4). Similar data for $90 \%$ breakthrough concentration $(\alpha=0.90)$ are shown in Fig. 5.

\section{Corrections for Retardance and First-Order Decay}

Recall that the definition of retardance is $\mathrm{R}=1+\rho \mathrm{K}_{\mathrm{d}} / \theta$ and is interpreted as the ratio of the velocity of the water to the velocity of the solute. Therefore, penetration times are linear in R. Penetration times from Figs. 2-5 can be adjusted for any retardance factor $\mathrm{R}$ as follows:

$t_{p}(\alpha, R)=R t_{p}(\alpha)$,

where $\alpha$ is the level of $c / c_{0}, t_{p}(\alpha)$ is the penetration time for $R=1, R$ is the retardance factor, and $t_{p}(\alpha . R)$ is the adjusted penetration time accounting for retardation.

From the first-order decay process, the concenIration $c(x, t)$ is adjusted by multiplying by the amount of decay. That is, the concentration accounting for first-order decay can be written as

$c(x, t, \mu)=c(x, t) \exp (-\mu t)$,

so that the resulting concentrations from the penetration time analysis are adjusted by the factor exp $(-\mu \mathrm{t})$.

\section{Selected Examples}

A few brief examples are presented in this section to illustrate (in a user-oriented fashion) application of the relationships described above to analysis and development of migration barriers. Notice that in all examples we assume $R=1$. If tie contaminant is subject to retardation $(R>1)$, then all times would be multiplied by $R$.

\section{Example 1}

Estimate the probable range of penetration times for a $30-\mathrm{cm}$ migration barrier if field estimates of pore water velocity range from 1 to $100 \mathrm{~cm} / \mathrm{yr}$. First, define the initial penetration time as the time it takes the contaminant to reach $10 \%$ of the source concentration $\left(\alpha=c / c_{0}=0.10\right)$ for $x=30 \mathrm{~cm}$ and $v=1$ to $100 \mathrm{~cm} / \mathrm{yr}$. Enter the vertical axis in Fig. 4 at $\mathrm{v}=1.0$ $\mathrm{cm} / \mathrm{yr}$ and read a value of $t_{\mathrm{p}}(0.10)=0.73 / \mathrm{yr}$ at a thickness of $x=30 \mathrm{~cm}$. Next, enter the vertical axis in Fig. 4 at $v=100 \mathrm{~cm} / \mathrm{yr}$ and read $\mathrm{t}(0.10)=0.147 \mathrm{yr}$ at the top of the curve. Therefore, a likely range for $t(0.10)$ is 0.15 to $0.73 / \mathrm{yr}$ if the pore water velocity ranges from 1.0 to $100 \mathrm{~cm} / \mathrm{yr}$ and the other parameters in Eqs (2-6) are as specified in Fig. 4. 


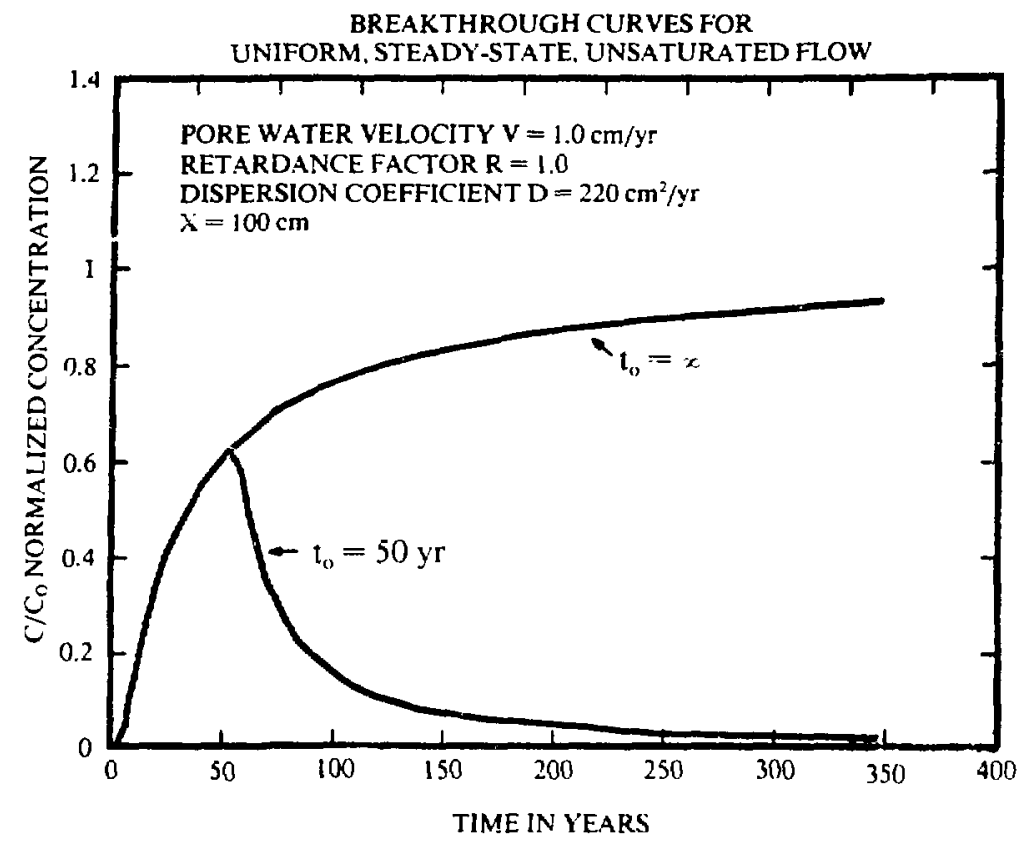

Fig. 1. Illustration of breakthrough curves for pulse input of finite duration $\left(t_{0}=50 \mathrm{yr}\right)$ and infinitc duration $\left(\mathrm{t}_{\mathrm{s}}=\mathrm{x}_{\mathrm{x}}\right)$.

UNIFORM, STEADY-STATE, UNSATURATED FLOW

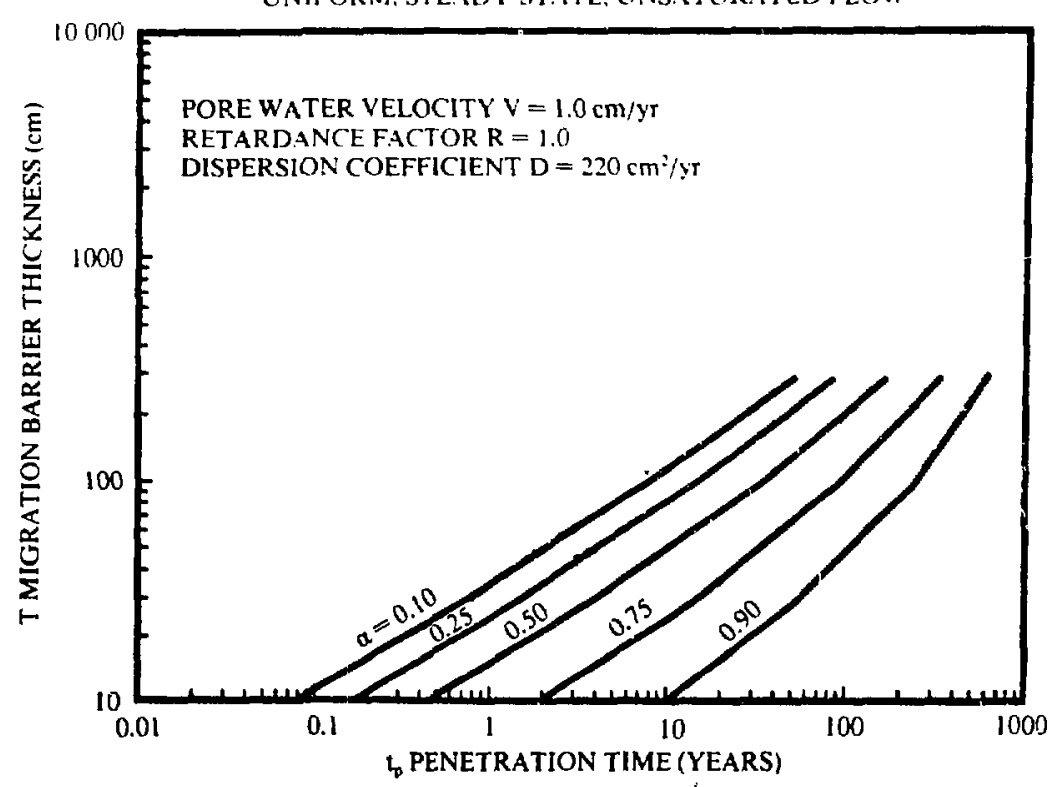

Fig. 2. Penetration time $t_{p}(\alpha)$ as a function of $\alpha, v, R, D$, and migration barrier thickness for $v=$ $1.0 \mathrm{~cm} / \mathrm{yr}$. 


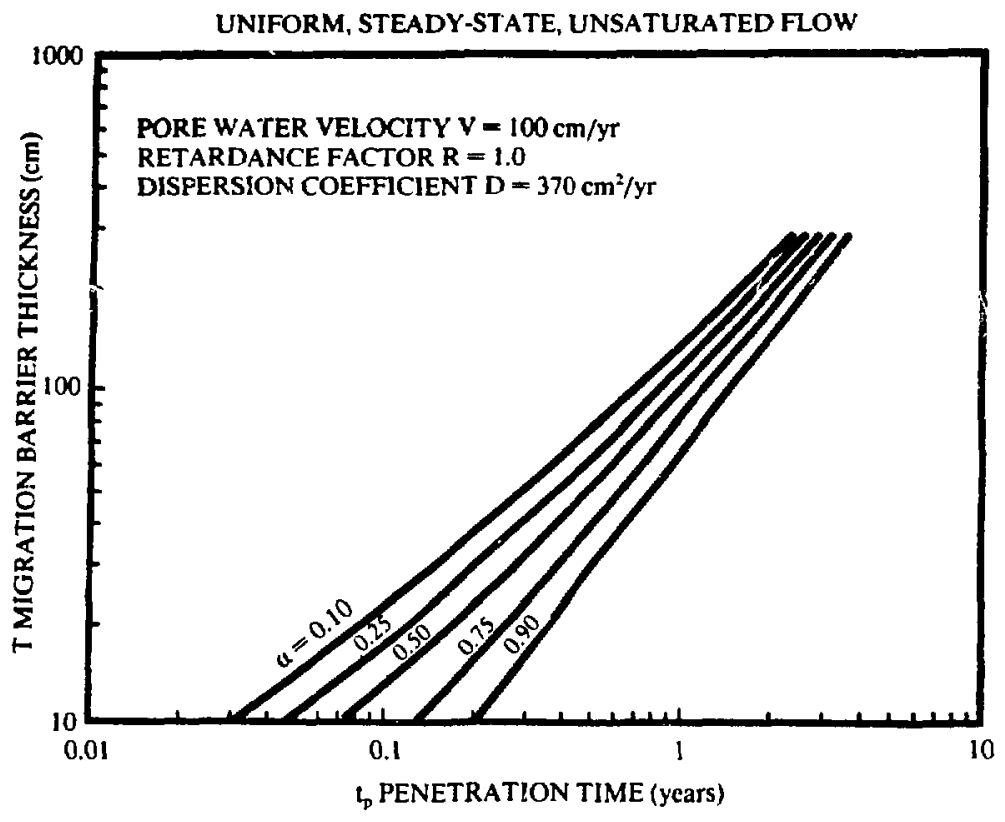

Fig. 3. Penetration time $t_{p}(\alpha)$ as a function of $\alpha, v, R, D$, and migration barrier thickness for $v=$ $100 \mathrm{~cm} / \mathrm{yr}$.

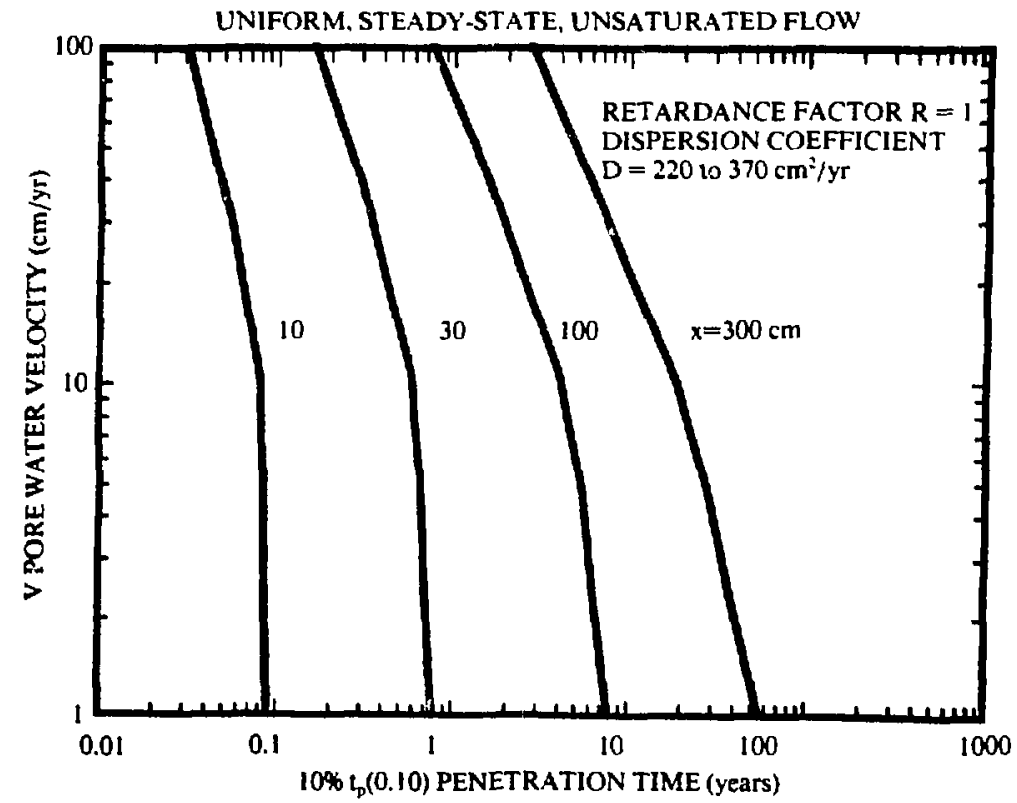

Fig. 4. Penetration time for $\alpha=0.10$ as a function of pore water velocity and migration barrier thickness. 


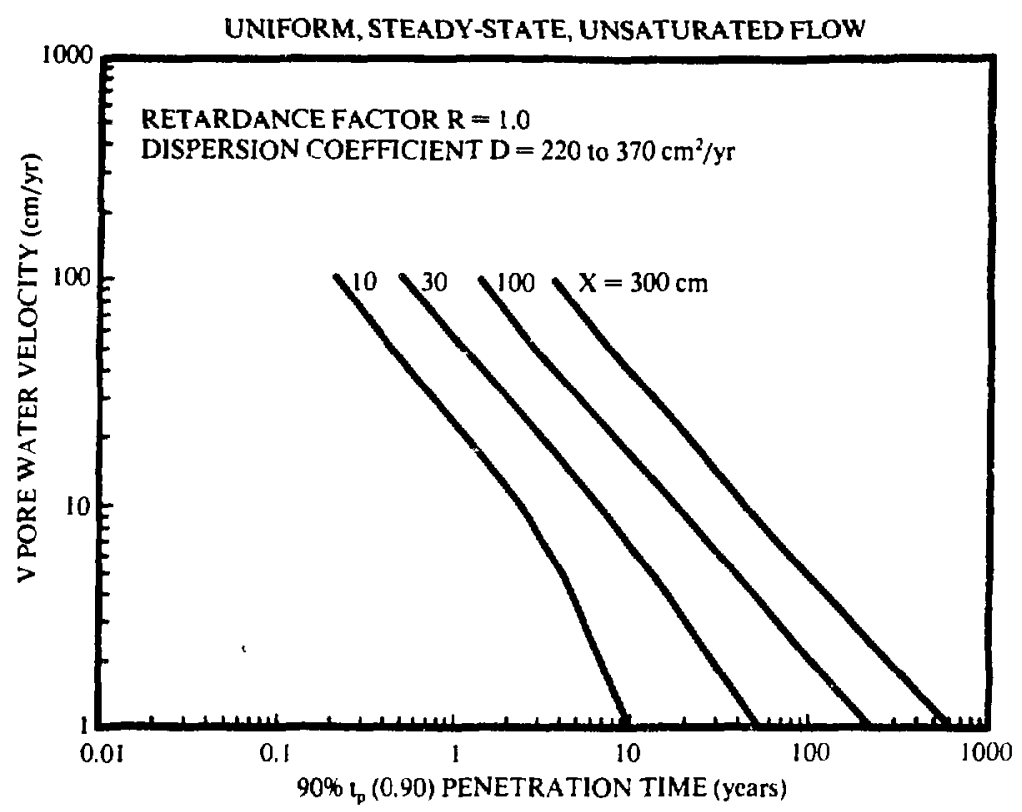

Fig. 5. Penetration time for $\alpha=0.90$ as a function of pore water velocity and migration barrier thickness.

Example 2

Approximate several points on the breakthrough curve for a constant concentration source term of strength. $c_{w}$, if the migration barrier is $50 \mathrm{~cm}$ thick and has a steady-statc pore water velocity of 1.0 $\mathrm{cm} / \mathrm{yr}$. Figure 2 shows penetration times for several values of $\alpha=c / c_{n}$ so that we can derive the following estimates directly from Fig. 2 [ $t_{p}(\alpha)$ in years]:

\begin{tabular}{|l|c|c|c|c|c|}
$\alpha=c / c_{o}$ & 0.10 & 0.25 & 0.50 & 0.75 & 0.90 \\
\hline$t_{p}(\alpha)$ & 1.9 & 3.7 & 9.3 & 31 & 102
\end{tabular}

Implications from these data include the following: (1) we might expect significant $(\alpha=0.10$ or $10 \%$ of source concentration) breaking through the migration barrier as early as 2 years, (2) within about 10 years, the breakthrough concentration might be as high as $50 \%$ of the source term, and (3) it might take as long as 100 years or more before the strength of the breakthrough concentration approached that of the source term. Another obvious implication of migration barrier failure, under these conditions, is that when breakthrough is first noticed $\left[t_{p}(\alpha=0.10)=1.9\right.$ $\mathrm{yr}$ in this example], the problem of increasing breakthrough concentrations continues for long periods, as in this case, for something like 100 years or more.
Therefore, migration barriers should be designed as a "second line system" in addition to surface water management systems. That is, if moisture flux through the trench cover and into buried wastes can be varied over orders of magnitude by surface water management techniques and this moisture flux provides the upper boundary condition or input to the migration barrier, then surface water management can have significant effects on subsurface migration barrier performance.

Example 3

If $\alpha=0.10$ is a specified tolerance level for contaminant concentration on a migration tarrier breakthrough, estimate the duration or tutal amount of time that $c / c_{0}>0.10$ for a pulse input to a $100-\mathrm{cm}$ thick migration barrier if $\mathrm{v}=1.0 \mathrm{~cm} / \mathrm{yr}, \mathrm{R}=1, \mathrm{D}=$ $220 \mathrm{~cm}^{2} / \mathrm{yr}$, and $t_{0}$ in Eq (6) is 50 years. From Fig. 1 , the curve labeled $t_{0}=50$ years, estimate $c / c_{0}>0.10$ for time 7.4 years to about 123 years, or a total duration of about 116 years.

\section{E. Discussion}

The previous examples are admittedly simplified in terms of field applications or development of design criteria; however, they do illustrate how unsaturated flow and transport models [see Eqs 
(1-8) and the related discussion material] are applied in developing and evaluating migration barrier performance. Better models can, and will, be applied to develop more realistic migration barrier technology. However, these models are currently under development and/or are being validated This assessment is, in fact, supported by currently available expert opinion across a broad spectrum of scientific orientation (see Arnold et al. 1982 ar. $^{\prime}$ the discussion summary on pp. 337-343). Quite simply, migration barrier technology is dependent on development of fieldapplicable and ialidated unsaturated flow and transport models that accurately describe complex SLB field systems. These field validation studies are of necessity long term (note the time scale on the horizontal axis of Fig. 1, and see the saturated hydraulic conductivity data presented in Tables $I$ and II) and, by their nature, are complex and difficult.

However, the concepts illustrated by the figures and examples here are, in fact, useful in developing design concepts for migration barriers. Although substantial uncertainty exists (as evidenced by the several "orders of magnitude" examples discussed), progress is being made as illustrated by recent publications such as Apps et al. (1982) and by Figs. $1-5$ in this report.

\section{COMPARISON OF POSSIBLE BARRIERS AND RECOMMENDATIONS}

Whereas preceding sections of this report have dealt with analytical solutions to the solute transport equations to approximate the behavior and design criteria of migration barriers, the behavior of certain types of migration barriers in the field does not always agree with this theoretical behavior. As was stressed earlier, the major explanation for this disparity is.that a migration barrier is only one component in a complex, interdependent SLB system. For any one site, this system is usually not fully characterized as far as the site's hydrology, soil mechanics, plant and biological processes, and many other physical and chemical properties. In addition, very little, if any, field experience exists as far as trying to implement rilany of these improved SLB technology designs into successfully emplaced field installations. Thus, the succeeding section of this report deals with some of the limited field observations that have been made as far as comparing advantages and disadvantages of various types of migration barriers.

\section{A. Comparison of Materials}

Important criteria in selecting a material to line and cap a disposal pit include the expected service life and the associated costs. Such a comparison is presented in Fig. 6. Although many of these materials have been used to line sanitary landfills and ponds containing hazardous industrial waste or uranium mill tailings, by far the largest amount of experience has been associated with the use of these materials in water retention facilities. The life expectancies that have been conservatively estimated for water retention structures may be reduced by variable amounts if the nuaterial is exposed to acidic effluent, salts, organic solvents, etc., or if the material is subjected to significant amounts of differential settlement.

Past experience indicates that synthetic menbranes, in general, have an expected life of around 25 yr (Pertusa 1980). Using polymeric membranes to contain wastes is a relatively new field, with little published information indicating how the membranes will withstand the environmental or chemical stresses to which they may be subjected over a span of years. Although some research is under way to determine the long-term effects of different chenicals and leachates on the membranes, these experiments have lasted, at most, $3 \mathrm{yr}$, which is far too short a time to provide data of the type needed. Although the membranes may provide a temporary solution to the containment of radioactive waste, they do not appear to provide optimum containment. They are costly and, currently, the primary use of these membranes is in storage ponds, where location and repair of leaks is simplified.

Much more experience is associated with the use of concrete and asphalt in both hydraulic facilities and radioactive waste disposal. For example, pretreatment of liquid radioactive waste may involve mixing it with polymer-impregnated concrete or bitumen to form a matrix. Asphalt, however, appears to be more cost effective in retaining radioactive waste than is concrete. As illustrated in Fig. 6, there is a significant variation in price, depending on the type of asphalt, with paving asphalt being the most economical, and catalytically blown asphalt the most expensive. The life expectancy of exposed asphalt is only on the order of $20 \mathrm{yr}$. However, its estimated service life can be greatly increased with the use of proper soil covering and construction techniques. Major disadvantages associated with the usc of asphalt, as opposed to concrete, as a cap or liner include the possible degradation of asphalt by organic 


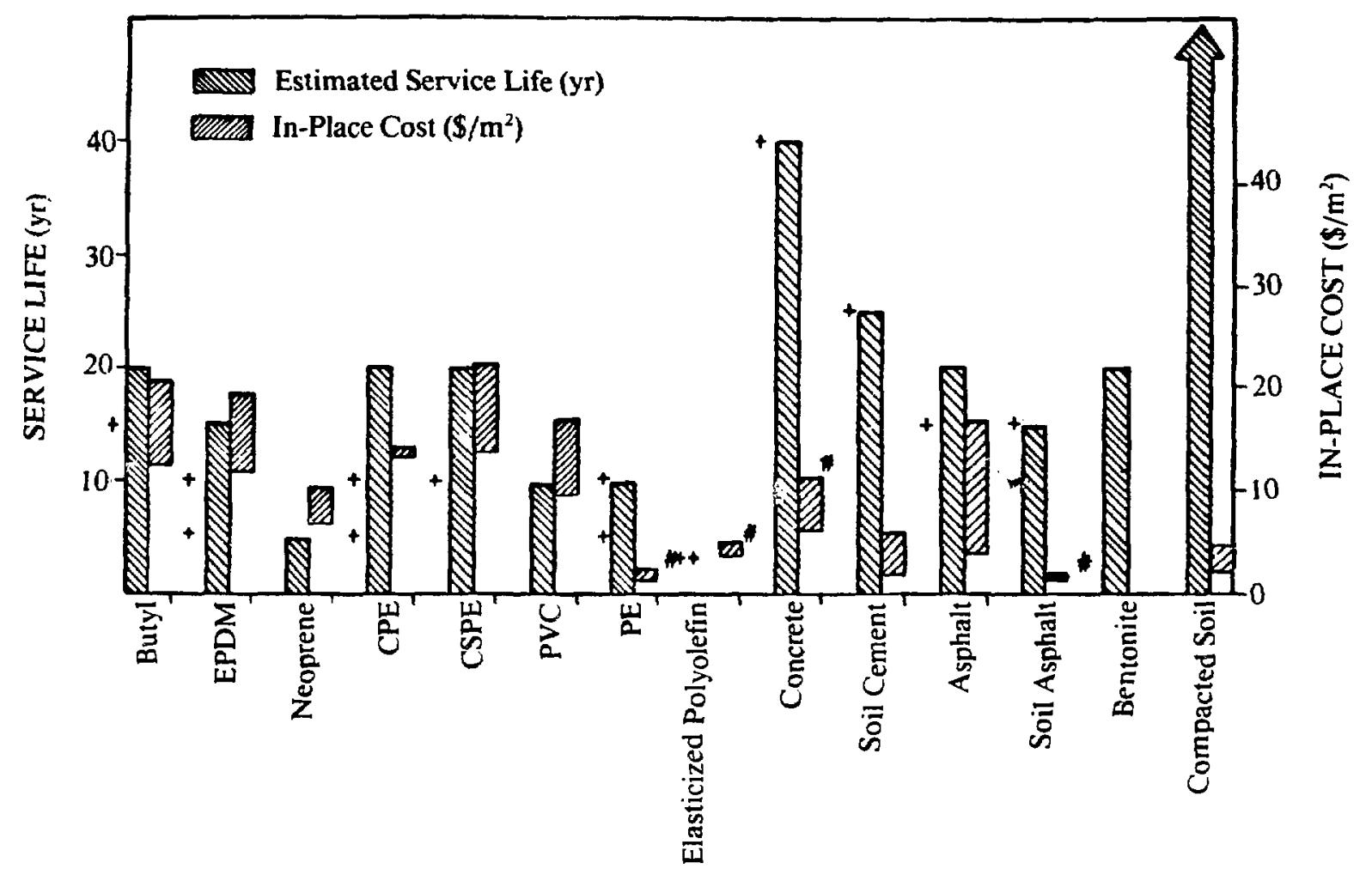

Fig. 6. Comparison of expected service life vs in-place cost (1976). Unless noted, service life estimate is for water-retaining structures. $\mathrm{A}+$ is the radwaste estimate; ++ means no estimate is available (because the liner was invented in 1975). Cost estimate includes excavation, installation, backfilling, compaction, and seeding (glacial till). A \# means the cost does not include construction of subgrade or earth cover.

compounds in the waste and cracking if it is exposed to significant amounts of differential settlement.

At present, soil barriers appear to offer the most economical solution for a given waste containment time. Unlike manmade materials that deteriorate with time, soils are extremely stable. Evidence of the stability and attenuation capabilities of soils is demonstrated by the "Oklo phenomenon." A.bout 2 billion years ago, a naturally occurring geological reactor began to produce fission products in what is now Oklo, Gabon (Africa). During this time span, as much as 10 metric tons of fission products were successfully stored in the ground. Although most of the heavy elements remained relatively fixed, the radionuclides that have migrated significantly during this period include $\mathrm{Kr}, \mathrm{Xe}, \mathrm{Rb}, \mathrm{Cs}, \mathrm{Sr}, \mathrm{Ba}, \mathrm{Mo}$, and I (Walton and Cowan 1975). The mobility of Cs and $\mathrm{Sr}$ is of particular interest from the nuclear disposal point of view.

\section{B. Recommendations}

The following discussion will deal with possible design recommendations for caps and liners that may mitigate many of the problems currently occurring at some of the low-level radioactive waste disposal sites.

1. Trench Caps. Because most of these problems could be eliminated or at least reduced if moisture could be prevented from contacting the waste, a properly designed cap is critical. The waste might be kept dry by constructing the cap of a somewhat permeable material with the possible use of drains to intercept any infiltrating moisture and divert it away from the disposal pit. The cap should also be either structurally sound (e.g., concrete) or flexible and capable of self-healing if deformed by settlement of poorly compacted waste. In addition, the cap must be resistant to plant roots and burrowing animals. 
One of the major problems that reduces the effectiveness of clay as a cap is its tendency to crack when exposed to cycles of wetting and drying or freezing and thawing. Although more research is necessary, mixtures consisting mostly of sand, but with some clay, would be expected to undergo little cracking when subjected to variations in moisture or temperature. Saturated coefficients of permeability on the order of $10^{-8} \mathrm{~cm} / \mathrm{sec}$ are possible using mixtures of bentonite and silty sand, and it may be possible to achieve permeabilities as low as $10^{-10}$ $\mathrm{cm} / \mathrm{sec}$ (Pertusa 1980). Corresponding hydraulic conductivities for unsaturated cenditions would be even lower.

The data summarized in Table II suggest that clay barriers may be very effective in slowing water and contaminant migration; however, these barriers do have potential problems. Previous research efforts with Wyoming bentonite as plant intrusion barriers have shown that root penetration of the clay layer can cause shrinkage of the layer (and thus potential subsidence). Data reported by Hakonson et al. (1982b) suggested that plant roots extracted water from the clay layer much faster than it could be rewetted (because of low hydraulic conductivity), with the result that the layer shrank to about haif its original thickness in a singl: growing season. Subsequent experiments in which the lysimeters containing the clay layers were not irrigated showed that (because of plant root water extraction) layer shrinking continued until the integrity of the clay layer was completely destroyed. In the 25 -cm-diam lysimeter column, cracks on the order of $1-5 \mathrm{~cm}$ were opened during the drying process. Therefore, if plant roots are likely to enter a clay barrier and if the clay has a high shrink/swell potential with changes in water content, then we must not recommend it as a water and contaminant migration barrier. Either roots must not enter the clay barrier to extract moisture or the barrier should not shrink or swell in response to changing moisture conditions.

As a practical method for predicting field performance of clay liners as migration barriers, recent analyses (Daniel 1984) have suggested that field hydraulic conductivity of clay liners may be as much as 10 to 1000 times larger than laboratory predicted values. The user is warned of this potential 1 to 3 orders-of-magnitude difference in laboratory test results and actual field performance of clay barriers. Clearly, this is an area where additional long-term research is needed (i.e., extending laboratory results to predict field performance).

Cracking of the trench cap may also result from tensile strain caused by settlement of the support.
This type of cracking may be reduced by compacting at a moistur: content higher than the optimum moisture content, which tends to produce plastic behavior. However, compaction at a high moisture content also leads to shrinkage cracking during periods of subsequent desiccation. A solution under investigation at the University of Texas at Austin involves the use of soil reinforcement fabric, which might provide enough strength and bonding to reduce desiccation and settlement cracks. However, it is suspected that the fabric may be subject to many of the field problems associated with synthetic membranes.

Assuming the water table is sufficiently deep, the cover should be thick enough to ensure that any cracks that do form do not penetrate through a significant portion of the cap. Because compacted clay or sand/clay mixtures do not deter burrowing animals or penetration of plant roots, the cap must also be thick enough to reduce the possibility of intrusion. Compacting the soil might aid in retarding plant or animal intrusion. However, the release of radionuclides by plant uptake is still a possibility, especially in an arid region. The escape of radioactive gases is also a potenıial problem. If no measures are taken to reduce the production of radioactive gases [such as ${ }^{14} \mathrm{CH}_{4},{ }^{14} \mathrm{CO}_{2}$, and $\mathrm{CH}_{3} \mathrm{~T}$ (tritiated methane)] (e.g., by incinerating the organics), increasing the thickness of the cap so that cracks do not penetrate to a significant depth would lessen the release rate to the atmosphere. A more effective gas barrier, such as a moist clay cap, could cause the gas to diffuse laterally, which might become even more of a problem.

A modified design might incorporate multipurpose gravel or cobble layers into the cap as shown in Fig. 7. Depending on availability, gravel may be only slightly more expensive than compacted clay (Fig. 7). For unsaturated conditions, any infiltrating moisture would be diverted laterally in the soil overlying the gravel layer, [i.e., the flow would be governed by the wick effect (DePoorter et al. 1982)]. With saturated conditions, water would flow into the gravel layer, which would serve as a drain, channeling the water away from the disposal pit. Other advantages of the layer of cobble or gravel include the minimization of plant root penetration and the deterrence of burrowing animals (Brunner and Kelley 1972, Cline et al. 1979, DePoorter et al. 1982, Hakonson et al. 1982b). The gravel layer might also serve as a collection system for escaping radioactive gas. Vents and appropriate filters could be used to collect and treat the gas. 

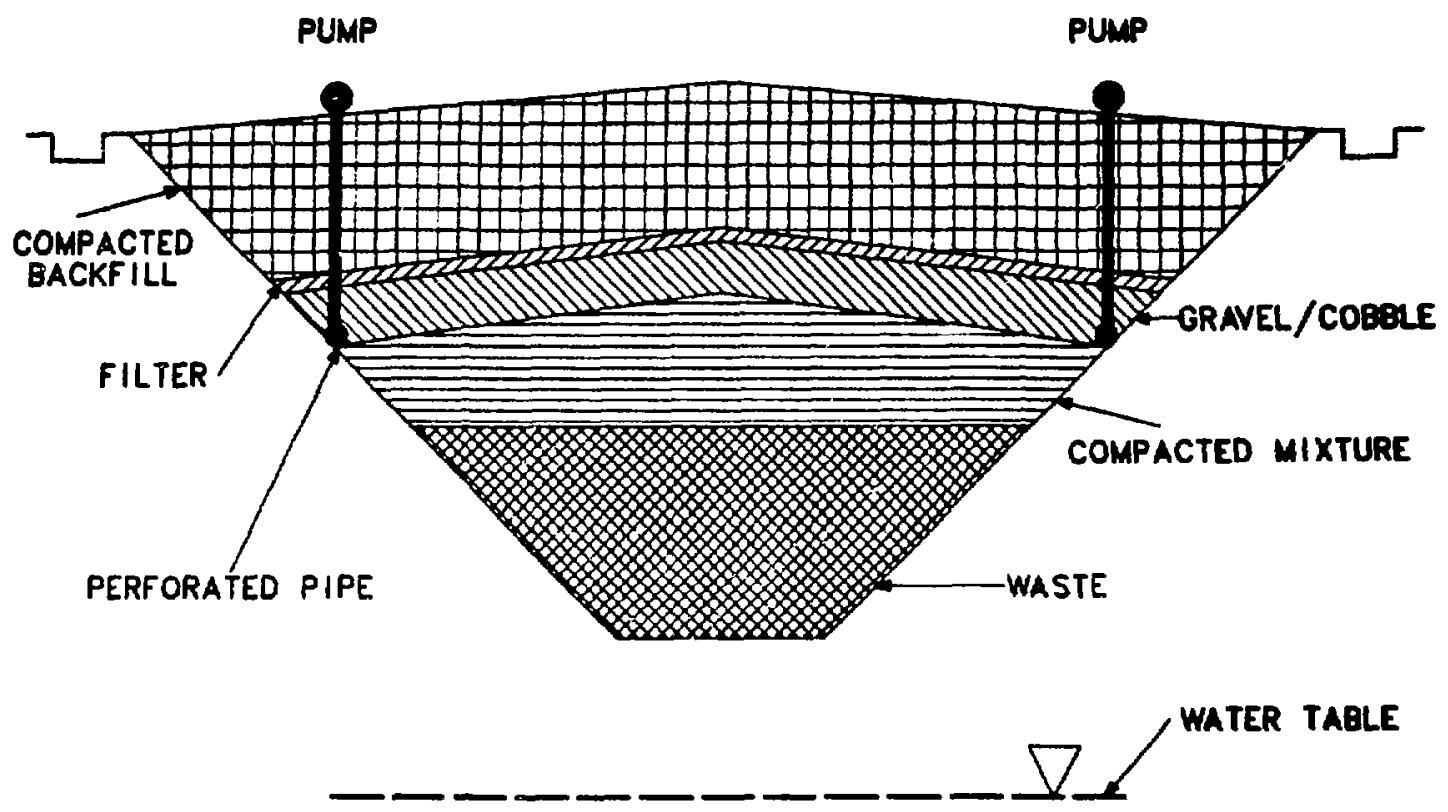

Fig. 7. Compacted soil cap with drain. [Optional: pumps and perforated pipes (Pertusa 1980)].

For the gravel layer to fulfill its design functions, it must be maintained free of fines. I graded filter, thick enough to remain effective if postconstruction settlement occurs, would be necessary to prevent the overlying soil from migrating into the gravel layer. A cobble layer may not be economically justified because it could require two or more graded filters, which might become expensive. A filter cloth could be used ir. lieu of a graded filter, although its longterm effectiveness is doubtful. Other problems associated with a filter cloth include the possibility of fines passing through the cloth if the overlying soil has a silt or clay content of more than $50 \%$ (Dunham and Barret 1974). In addition, improper placement of the filter cloth may result in lack of continuity or the cloth may be degraded by soil organisms or ingested by rodents.

The sand/clay layer below the layer of gravel (Fig. 7) would serve as a somewhat permeable barrier, which would guide infiltrating moisture away from the trench during prolonged rains. As mentioned previously, a sand/clay mixture would not be expected to crack appreciably when exposed to cycles of wetting and drying.

Although not much is known about gravel/cobble biointrusion barriers functioning as a subsurface wick or capillary barrier system in a trench cap, field research at Los Alamos has shown that gravel/cobble biobarriers can have an effect on the subsurface migration of water and radionuclides
(Perkins and Cokal 1984). This field research was performed in two 6.1-m-deep caissons with a diameter of $3.05 \mathrm{~m}$, one of which contained a 1-m-thick gravel/cobble biobarrier (Fig. 8). In the caisson without a bioharrier, soil water movement at the zone containing $\mathrm{Cs}$, $\mathrm{Sr}$, and Co tracers did not occur as sudden breakthrough surges, as it did in the caisson with the biobarrier. For the same water inputs, the biobarrier treatment exhibited greater migration of tracers than did the tuff treatment, as is typically shown for the Co data (Fig. 9). This effect was attributed to greater nonuniformity in water content, more water infiltration, and the "pulse" type of change in water content at or near the tracer layer in the biobarrier treatment compared with the tuff treatment.

Thus, a gravel or cobble layer incorporated into the cap may result in problems if the soil in the region adiacent to the gravel becomes saturated. This may be solved by perforated pipes and pumps (Fig. 7). Another solution would be to make certain the layer above the gravel/cobble layer performed as a satisfactory wick layer. This would mean that a gravel/cobble layer in the trench cap would have a significant slope (the slope in the caisson experiment shown in Fig. 8 is equal to zero) and slope length and that the thickness of the overlying capillary layer would also be adequate in this configuration to effectively transmit subsurface water. 


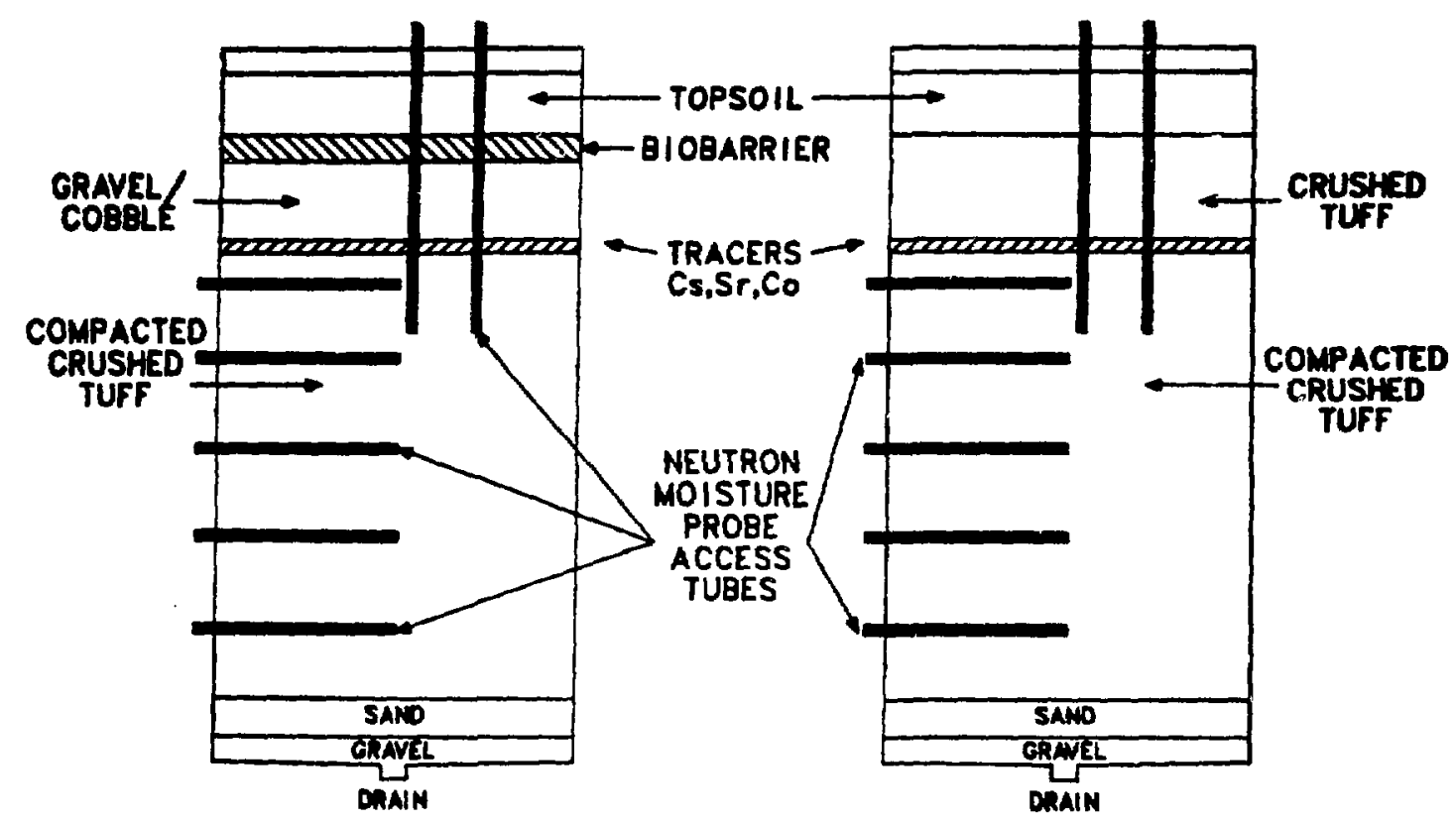

Fig. 8. Biointrusion barrier/transport experiment.

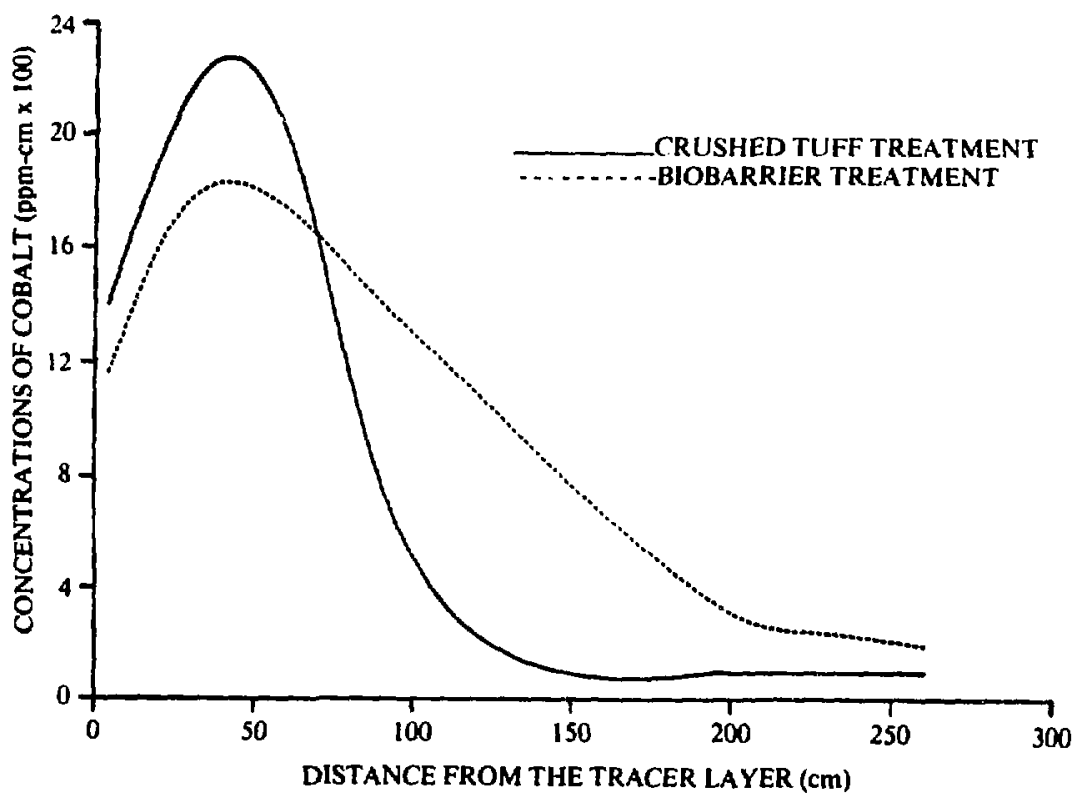

Fig. 9. Vertical distribution of a cobalt tracer in caissons. 
2. Trench Liners, The liner retards the movement of radionuclides away from the disposal pit, as well as lateral flow of water into the trench. To satisfy this requirement, the liner must be nearly impervious and not susceptible to degradation by chemical reactions or radiation exposure. Compacted clay or sand/clay mixtures are resistant to attack by many chemicals and attenuate cationic radionuclides. Calcareous clays, lowever, should be avoided if the effluent is acidic.

The minimum design thickness of a compacted soil liner can vary considerably relative to the soil's conductivity. However, growth of microorganisms, changes in the chemistry of the fluid flowing through the liner (Olson and Daniel 1979), and precipitation of elements or compounds out of solution can, with time, alter the conductivity. Stratification resulting from poor bonding between lifts during construction may also cause unexpectedly high permeabilities.
Sheepsfoot rollers could be used to lessen stratification. Any cracking that might occur during construction could be reduced and possibly eliminated with the use of spray-on asphalt membranes.

Lining the sides of the disposal pit (Fig. 10) will minimize the possibility that radioactive leachate could migrate laterally. Whether to line the floor of the pit (Fig. 11) may depend on several factors, such as the amount of precipitation and geology of the area. In essence, it would depend on whether a significant amount of contaminants would be released to the biosphere or whether dilution would mitigate future problems. If the bottom of the pit is lined, a collection system would be necessary. This system could consist of a blanket of coarse-grained material on top of the floor of the pit, with a gentle slope to a sump area that is drained through one or more riser pipes.

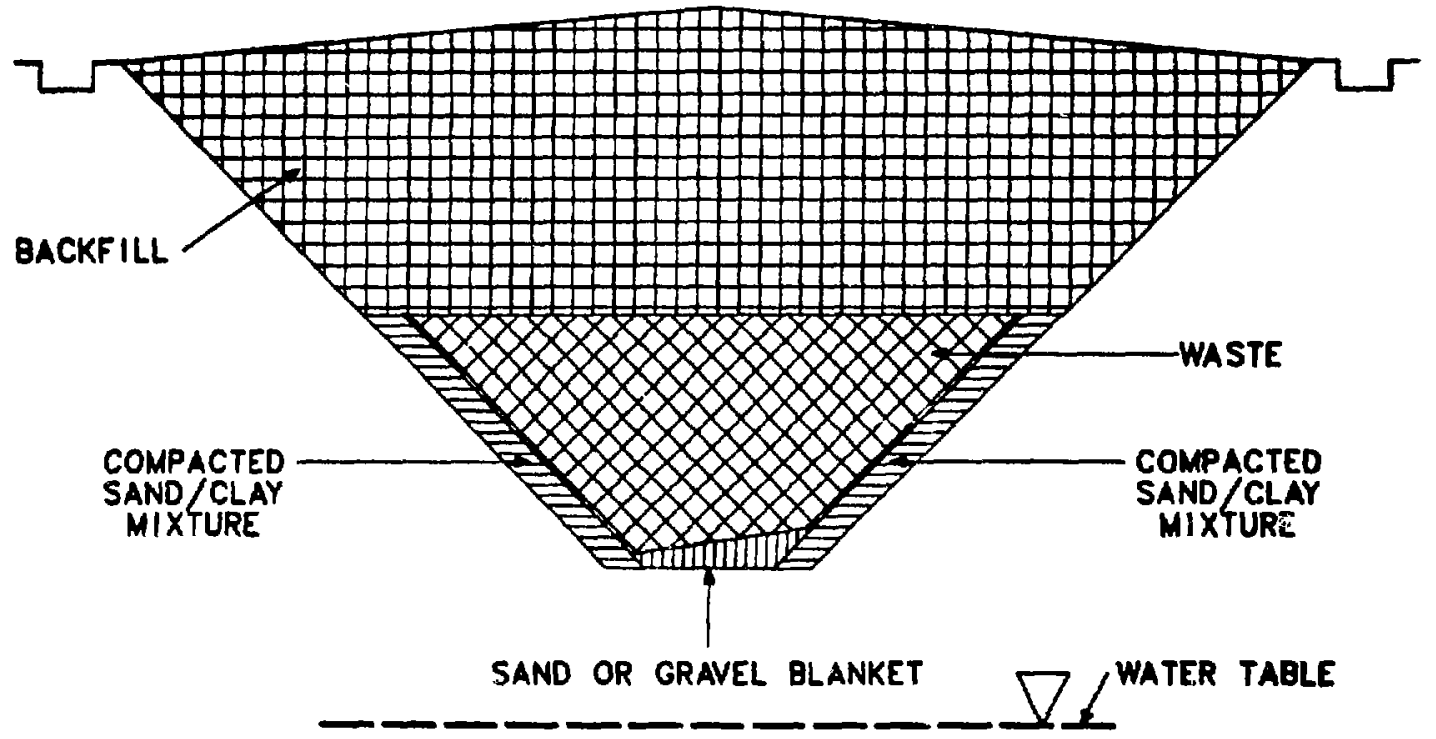

Fig. 10. Compacted sand/clay mixiure used to line only the sides of the disposal pit (Pertusa 1980). 


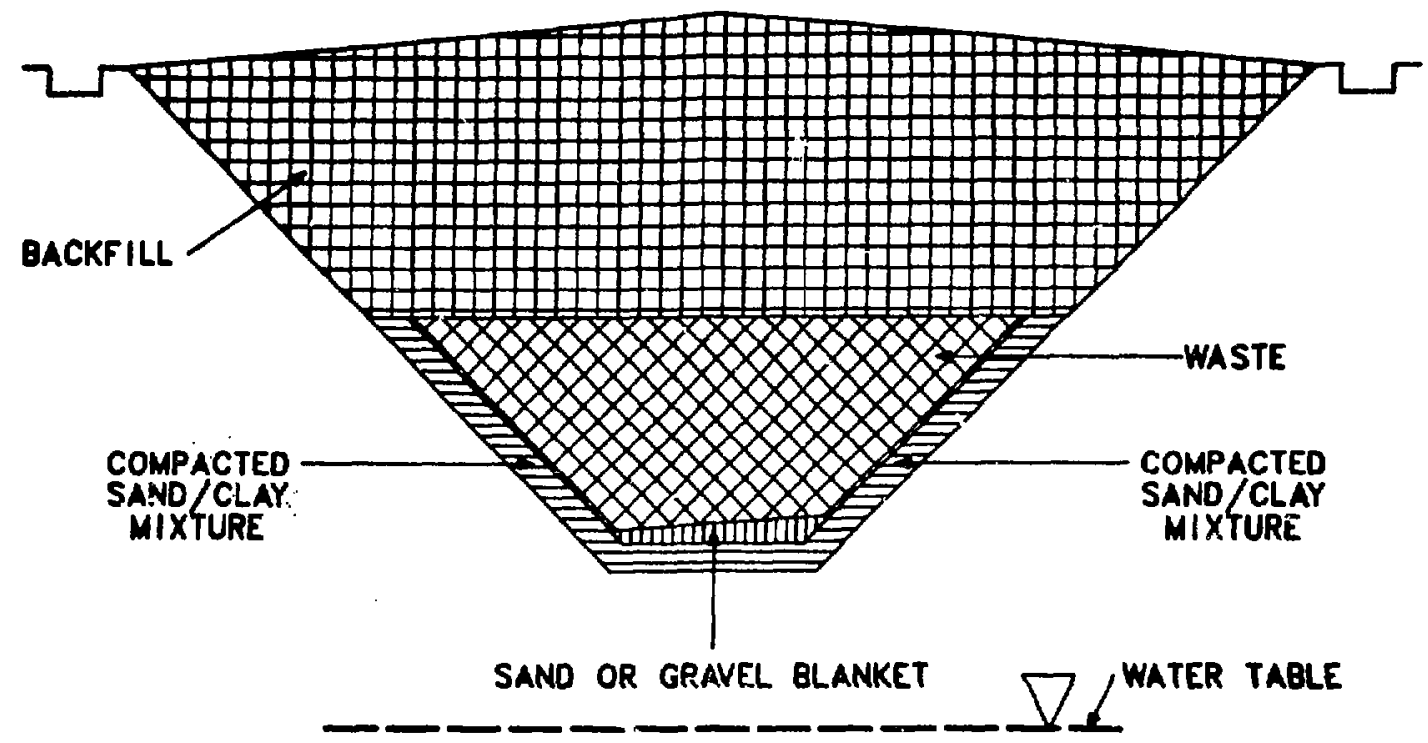

Fig. 11. Compacted sand/clay mixture used to iine sides and bottom of disposal pit [may require pump (Pertusa 1980)].

\section{NEEDED IMPROVEMENTS AND EXPERI- MENTS}

Several recent publications have documented needed improvements and experiments in considerable detail. It is beyond the scope of this brief report to repeat these assessments, except to emphasize areas identified earlier. Material in this report by Arnold et al. (1982) presents an excellent baseline for future studies, especially those related to modeling and field studies. A recent research plan (Wobber et al. 1983) identified scientific needs for improved understanding of basic mechanisms. These references, together with those cited earlier with respect to clay and unsaturated flow and transport modeling, and the material presented here suggest the following assessments:

1. Current modeling capabilities are inadequate to properly design and evaluate the performance of migration barriers. There are major information gaps with respect to physical, chemical, and biological processes controlling long-term migration barrier performance at SLB facilities.

2. Migration barrier performance is very much a function of interactive processes operating to control water dynamics at SLB facilities. Traditional engineering solutions, which do not include analyses of the interactive factors, have led to numerous
SLB failures (see Hakonson et al. 1982a and their cited references for examples). Future designs that ignore the interactive factors controlling the performance of SLB facilities are likely to reproduce many of the failures of the past, including losing the integrity of migration barriers. Simple examples are root penetration of clay barriers resulting in barrier failure (Hakonson et al. 1982b) and the inability to predict field performance of clay liners (Daniel 1984).

3. Migration barrier design criteria should include surface water balance calculations because they provide the initial and upper boundary conditions for subsequent subsurface flow and transport calculations. Without the conceptual and mathematical linkage between surface, near-surface, and subsurface processes, migration barrier designs will probably always remain suboptimal. This required linkage must also include physical, chemical, and biological processes and their interactions.

\section{ACKNOWLEDGMENTS}

We are pleased to acknowledge Maxine Lewis and Cindy Gamble for their efforts in preparing this manuscript and the various reviewers for their helpful suggestions. 


\section{REFERENCES}

Abeele, W. V., "Geotechnical Characteristics of Bentonite/Sandy Silt Mixes for Use in Waste Disposal Sites," Los Alamos National Laboratory report LA-10i01-MS (1984).

Abeele, W. V., and G. L. DePoorter, "Field Scale Determinations of the Saturated and Unsaturated Hydraulic Conductivity of Porous Materials. I. Crushed Bandelier Tuff," Los Alamos National Laboratory document LA-UR-83-1279 (1983).

Amoozegar-Fard, A., D. R. Nielsen, and A. W. Warrick. "Soil Su iute Concentration Distribution for Spatially Varying Pore Water Velocities and Apparent Diffusion Coefficients," Journal of the Soil Science Society of America Proceedings 46, 3-9 (1982)

Apps, J. A., C. L. Carnaham, P. C. Lichtner, M. C. Michel, D. Perry, R. J. Silva, O. Weres, and F. A. White, "Status of Geochemical Problems Relating to the Burial of High-Level Radioactive Waste," Lawrence Berkeley Laboratory report LBL-1 5103 (1982).

Arnold, E. M., A. W. Gee, and R. W. Nelson, "Symposium on Unsisady Flow and Transport Modeling," Battelle Pacific Northwest Laboratories report PNL-SA-10325 (1982).

Brunner, D. R.. and D. J. Kelley, "Sanitary Landfill Design and Operation," US Environmental Protection Agency, Solid Waste Managenent Office report EPA-SW-65ts (1972).

Cline, J. F., G. M. Holter, W. H. Richard, and E. L. Klepper, "Experimental Design for Demonstration of Bio-Barriers Placed in a Simulated Burial Trench," Battelle Pacific Northwest Laboratories 1eport BNWL-2035 ( 1977 ).

Daniel, D. E., "Predicting Hydraulic Conductivity of Clay Liners," Journal of Geotechnical Engineering 110(2), 285-300 (February 1984).

DePoorter, G. L., W. V. Abeele, B. W. Burton, T. E. Hakonson, and B. A. Perkins, "Shallow Land Burial Technology Development-Arid," in "Proceedings of the Fourth Annual Participants' Information Meeting-DOE Low-Level Waste Management Program," Oak Ridge National Laboratory Report ORNL/NFW-82/18 (October 1982).
DePoorter, G. L., and T. E. Hakonson, "Novel Experiments for Understanding the Shallow Land Burial of Low-Level Radioactive Wastes," in The Scientific Basis for Nuclear Waste Management, S. V. Topp, Ed. (Elsevier Science Publishing Co., Inc., 1982), pp. 441-447.

DePoorter, G. L., W. V. Abeele, and B. W. Burton, "Experiments to Determine the Migration Potential for Water and Contaminants in Shallow Land Burial Facilities: Design, Emplacement and Preliminary Results," Waste Management '82 2, 649-655 (1982).

Duguid, J. O., "Status Report on Radioactivity Movement from Burial Grounds in Melton and Bethel Valleys," Oak Ridge National Laboratory report ORNL-5017 (1975).

Dunham, J. W., and R. Barrett, "Woven Plastic Cloth Filters for Stone Sea Walls," Journal of the Waterways, Harbors and Coastal Engineering Division 100(WW1), 13-22 (1974).

Hakonson, T. E., L. J. Lane, J. G. Steger, and G. L. DePoorter, "Some Interactive Factors Affecting Trench Cover Integrity on Low-Level Waste Sites," in "Proceedings of a Symposium on Low-Level Waste Disposal, Site Characterization and Monitoring," Oak Ridge National Laboratory report NUREG/CP-0028, CONF-820674, Vol. 2 (1982a).

Hakonson, T. E., G. C. White, and G. L. DePoorter, "Ficld Evaluation of Geologic Materials to Limit Biological Intrusion of Low-Level Waste Site Covers," Waste Management '82 2, 145-152 (1982b).

Hakonson, T. E., W. V. Abeele, L. J. Lane, G. L. DePoorter, B. A. Perkins, and J. W. Nyhan, "Shallow Land Burial Technology Development: Arid Site Program," Los Alamos National Laboratory document LA-UR-83-2992 (October 1983).

Hillel, D., Soil and Water, Physical Principles and Processes (Academic Press, New York, 1971).

Knisel, W. G., Ed., "CREAMS: A Field Scale Model for Chemicals, Runoff, and Erosion from Agricultural Management Systems," US Department of Agriculture Conservation Research Report No. 26 (1980). 
Lane, L. J., "Preliminary Report on Water and Contaminant Trarsport in the Subsurface Zone-A Joint Los Alamos/USDA-Agricultural Research Service Study," Los Alamos National Laboratory document LA-UR-83-2994 (1983).

Lane, L. J., and J. J. Stone, "Water Balance Calculations, Water Use Efficiency and Above Ground Net Production," Hydrology and Water Resources in Arizona and the Southwest 13, 27-34 (1983).

Lane, L. J., "Surface Water Management: A User's Guide to Calculate a Water Balance Using the CREAMS Model," Los Alamos National Laboratory report LA-10177-M (1984).

Meyer, G. L., "Preliminary Data on the Occurrence of Transuranium Nuclides in the Environment at the Radioactive Waste Burial Site Maxey Flats, Kentucky," US Environmental Protection Agency report EPA-520/3-75-021 (1976).

Nyhan, J. W., and L. J. Lane, "Use of a State-of-theArt Model in Generic Designs of Shallow Land Repositories for Low-Level Wastes," Waste Management' '82 2, 235-244 (1982).

Olsen, R. E., and D. E. Daniel, “Field and Laboratory Measurement of the Permeability of Saturated and Partially Saturated Fine-Grained Soils," in "Proceedings, Permeability and Groundwater Contaminant Transport," ASTM Special Technical Publication No. 746, pp. 18-64 (1979).

Papadopoulos, S. S., and J. J. Winograd, "Storage of Low-Level Radioactive Wastes in the GroundHydrogeologic and Hydrochemical Reactors," US Geological Survey open file report 74-344 (1974).

Perkins, B., and E. Cokal, "Subsurface Moisture Regimes and Tracer Movement Under Two Types of Surface Treatments," Los Alamos National Laboratory report (in press), 1984.

Pertusa, M., "Evaluation of Caps and Liners for LowLevel Radioactive Waste Disposal Pits," M.S. thesis, University of Texas at Austin (1980).

Polzer, W. L., and L. J. Lane, "Field Studies and Modeling of Chemical Processes in the Unsaturated Zone," Los Alamos National Laboratory document LA-UR-84-445 (1984).
Rawls, W. J., D. L. Brakensiek, and K. E. Saxton, "Estimation of Soil Water Properties," Transactions of American Society of Agricultural Engineers Special Edition 25, 1316-1320 (1982).

Simmons, C. S., "A Stochastic-Convective Ensemble Method for Representing Dispersive Transport in Groundwater, Project 1406-1," Battelle Pacific Northwest Laboratories report CS-2558 (1982).

Skaggs, R. W., and R. Khaleel, "Infiltration," in Hydrologic Modeling of Small Watersheds, ASAE Monograph No. 5, C. T. Haan, H. P. Johnson, and D. L. Brakensiek, Eds. (American Society of Agricultural Engineers, 1982).

Travis, B. J., "TRACR3D: A Model of Flow and Transport in Porous/Fractured Media," Los Alamos National Laboratory report (in press).

van Genuchten, M. Th., and W. J. Alves, "Analytical Solution of the One-Dimensional Convective-Dispersive Solute Transport Equation," US Department of Agriculture Tecnnical Bulletin No. I66I (1982).

Walton, R. D., Jr., and G. A. Cowan, "Relevance of Nuclide Migration at Oklo to the Problem of Geologic Storage of Radioactive Wastes," in "The Oklo Phenomena," Proceedings of a Symposium in Libreville, IAEA, Vienna (1975).

Wierenga, P. J., "Solute Distribution Frofiles Computed with Steady-State and Transcient Water Movement Models," Journal of the Soil Science Societ!' of America 41, 1050-1055 (1977).

Wobber, F. J., R. E. Franklin, and R. L. Watters, "Geotechnical, Hydrological and Bio!ngical Cycling of Energy Residuals," US Department of Energy report DOE/ER-0156/I (1983).

Yu, C., W. A. Jester, and A. R. Jarrett, "Simultaneous Determination of Dispersion Coefficients and Retardation Factors for a Low-Level Radioactive Waste Burial Site," Radioactive Waste Management and the Nuclear Fuel Cycle 4(4), 401-420 (1984). 